\title{
Enucleation ratio efficacy might be a better predictor to assess learning curve of holmium laser enucleation of the prostate
}

Chang Wook Jeong, Jin Kyu Oh, Min Chul Cho, Jung-Bum Bae, Seung-June Oh

Department of Urology, Seoul National University Hospital, Seoul, Korea

\section{ABSTRACT}

Purpose: To appraise the evaluation methods for learning curve and to analyze the non-mentor-aided learning curve and early complications following the holmium laser enucleation of the prostate.

Materials and Methods: One-hundred and forty $(\mathrm{n}=140)$ consecutive patients who underwent HoLEP from July 2008 to July 2010 by a single surgeon (SJO) were enrolled. Perioperative clinical variables, including enucleation time, morcellation time, enucleation ratio (enucleation weight/transitional zone volume), enucleation efficacy (enucleated weight/enucleation time), enucleation ratio efficacy (enucleation ratio/enucleation time), and early complication rate were analyzed.

Results: Mean prostate volume was $62.7 \mathrm{~mL}$ (range 21-162) and preoperative International Prostate Symptom Score (IPSS) was 19.0 (4-35). Mean enucleation time and morcellation time were $49.9 \pm 23.8$ (S.D.) min and $11.0 \pm 9.7 \mathrm{~min}$, respectively. Median duration of postoperative indwelling catheter was 1 (1-7) day and median hospital stay was 1 (1-6) day. There were a total of 31 surgery-related complications in 27 patients (19.3\%), and all were manageable. There was an increasing trend of enucleation efficacy in the first 50 cases. However, enucleation efficacy was linearly correlated with the prostate size (correlation coefficients, $\mathrm{R}=0.701, \mathrm{p}<0.001)$. But, enucleation ratio efficacy could eliminate the confounding effect of the prostate size $(R=-0.101, p=0.233)$. The plateau of enucleation ratio efficacy was reached around the twenty-fifth case.

Conclusions: Our results demonstrated that the operative learning curve plateau is reached after about 25 cases. We propose that a more appropriate parameter for estimating the operative learning curve is enucleation ratio efficacy, rather than enucleation efficacy.

\section{ARTICLE INFO}

\section{Key words:}

Prostatic Hyperplasia; Lasers; Solid-State; Prostatectomy; Learning curve

Int Braz J Urol. 2012; 38: 362-72

Submitted for publication: July 21,2011

Accepted after revision: October 24, 2011

\section{INTRODUCTION}

Benign prostatic hyperplasia $(\mathrm{BPH})$ is a highly prevalent disease in elderly men. By the age of 60 , almost $60 \%$ of the cohort in the Baltimore Longitudinal Study of Aging had some degree of clinical BPH (1). The gold standard surgi- cal treatment for BPH is transurethral resection of the prostate (TURP) (2). Recent surgical techniques using lasers, such as photoselective vaporization of the prostate (PVP), holmium laser enucleation of the prostate (HoLEP) and thulium laser enucleation of the prostate (ThuLEP) have been popularized, with a number of reports document- 
ing their merits. HoLEP can confidently remove the entire enlarged adenoma through the use of Holmium:YAG laser in the natural tissue plane of the surgical capsule.

After the first clinical report by Gilling et al. in 1996, several randomized control trials have been reported (3). Compared to TURP or open prostatectomy, HoLEP has similar clinical outcome, lower postoperative complication rate and requires shorter hospital stay (4-8). In addition, HoLEP appears to be a true endourological alternative to open prostatectomy, because it can effectively treat a very large prostate $(9,10)$.

However, a steep operative learning curve may be the main hindrance to widespread use of HoLEP despite its advantages. Some researchers have argued that a surgeon needs between 20 and 30 cases of experience to attain competency $(6,11)$, while others have argued that up to 50 cases are needed $(12,13)$. This discrepancy comes mainly from the absence of an accurate way to evaluate the operative learning curve. Therefore, the purpose of this study was to evaluate a proper method to assess the learning curve to attain competency to perform enucleation of prostate using HoLEP.

\section{MATERIALS AND METHODS}

One-hundred and forty $(\mathrm{n}=140)$ consecutive patients who underwent HoLEP for the treatment of BPH from July 2008 to July 2010 were enrolled. All patients were treated by a single surgeon (SJO). Preoperatively, history taking, physical examination with digital rectal exam, International Prostate Symptom Score (IPSS), quality of life (QoL), frequency-volume chart, urinalysis, prostate-specific antigen, transrectal ultrasonography and pressure-flow study were performed on each patient.

Protocol for the HoLEP procedure is as follows. Each patient was placed in the lithotomy position under spinal anesthesia. The urethra was dilated with a $30 \mathrm{Fr}$ metal catheter prior to introduction of a working sheath. We used a 80W holmium laser (VersaPulse ${ }^{\circledR}$ PowerSuite $^{\mathrm{TM}}$, Lumenis, Yokneam, Israel), $550 \mu \mathrm{m}$ end-firing laser fiber (SlimLine $^{\mathrm{TM}}$, Lumenis, Yokneam, Israel), 26 Fr con- tinuous-flow resectoscope with a dedicated inner sheath, and a $30^{\circ}$ telescope (27040 XAL and 27005 BA, Karl Storz, Tuttlingen, Germany) for enucleation of adenomas. Enucleation was performed in 7 steps: 1. apical incision (lateral side to verumontanum), 2. bladder neck incision (5 and 7 o'clock positions) and conjoining transverse incision in front of verumontanum, 3. median lobe enucleation, 4. upward separation of lateral lobes, 5. longitudinal incision at 12 o'clock, 6 . downward incision of lateral lobes (to 3 and 9 o'clock side), and 7. connecting mucosal incision of apical prostate and enucleation of lateral lobes. For morcellation, we changed the resectoscope to a 26 Fr nephroscope with an adapter (27293 AA and 27040 LB, Karl Storz, Tuttlingen, Germany). Enucleated tissue was morcellated using a VersaCut ${ }^{\mathrm{TM}}$ morcellator (Lumenis, Yokneam, Israel). After the procedure, a 22 Fr Foley catheter was placed. Postoperatively, continuous bladder irrigation was applied as the occasion demanded. Usually, on the first or second postoperative day, the patient was discharged after removal of the urethral Foley catheter and spontaneous urination was confirmed.

Perioperative clinical variables, including enucleation weight, enucleation time, morcellation time, enucleation ratio (enucleation weight/transitional zone volume), enucleation efficacy (enucleated weight/enucleation time), enucleation ratio efficacy (enucleation ratio/ enucleation time), and early complications were recorded prospectively on a planned data registry form. These data were retrieved from the registered database, and then analyzed. This study was approved by the institutional review board (IRB) of Seoul National University Hospital.

Basic data were expressed by a descriptive method. Data for analysis of the learning curve were compared using the Student t-test, ANOVA and chi-square tests. To compare postoperative outcomes with preoperative outcomes, a paired samples t-test was used. To determine the relationship between enucleation efficacy and prostate volume, we performed linear regression analysis. All data were analyzed using SPSS version 17.0 (SPSS, Inc. Chicago, USA). For all statistical comparisons, significance was considered when $\mathrm{p}<0.05$. 


\section{RESULTS}

Patients' mean age was $68.9 \pm 6.1$ (S.D.) years, and mean preoperative prostatic specific antigen level was $3.5 \pm 3.1$ (S.D.) $\mathrm{ng} / \mathrm{mL}$. Mean prostate volume was $62.7 \mathrm{~mL}$ (range 21-162) and preoperative International Prostate Symptom Score (IPSS) was $18.8 \pm 7.7$ (S.D.). Mean preoperative maximum flow rate and postvoid residual were $9.6 \pm 4.7$ (S.D) $\mathrm{mL} / \mathrm{sec}$ and $86.5 \pm 124.6$ (S.D.) $\mathrm{mL}$, respectively. Various operative parameters related to learning curve were summarized in $\mathrm{Ta}$ ble-1 along with the number of cases experienced. There was no TURP conversion. Median duration of postoperative catheter indwelling and hospital stay was equal to 1 day (mean 1.61 , range 1-7 and mean 2.61, range 1-6, respectively). Preoperative and postoperative functional outcomes at 6 months are presented in Table- 2 .

A total of 31 surgery-related complications were recorded in 27 patients (19.3\%) (Table-3). However, all complications were mild and transient, so they were easily and properly managed. No patient developed stress urinary incontinence persistent for more than 3 months.

Enucleation efficacy had a strong linear correlation with total prostate volume (correlation coefficient, $R=0.701, p<0.001)$ and transitional zone volume $(\mathrm{R}=0.740, \mathrm{p}<0.001) \quad$ (Figure-1). Figure-2 summarizes the changes in operative parameters in the order of sequential cases. Enucleation efficacy was increased in the first 50 cases, however the enucleation ratio did not change significantly. The estimated prostate volume did not changed in the first 20 cases, compared to the next 20 cases (mean values 53.9 vs. $50.6 \mathrm{~mL}, \mathrm{p}=0.587$ ). However, there was significant increase in estimated prostate volume from case number 41 to 60 , compared to the prior 20 cases (mean value $70.1 \mathrm{~mL}, \mathrm{p}=0.015$ ). Enucleation ratio efficacy, having eliminated the confounding effect of prostate size, reached a plateau around the twenty-fifth case. And this parameter agreed with the surgeon's confidence in his operative skills.

\section{DISCUSSION}

TURP and open prostatectomy have been the treatments of choice for moderate $(30-80 \mathrm{~mL})$ and large ( $>80-100 \mathrm{~mL}$ ) size $\mathrm{BPH}$ prostates respectively $(2,14)$. TURP has been the standard surgical treatment for symptomatic BPH. TURP has high rate of success and imposes low economic burden. However, in $2.0-4.8 \%$ of cases, transfusion is required, and TURP syndrome, a dilutional hyponatremia that occurs when the irrigant is absorbed into the bloodstream, occurs in $1.1 \%$ of cases. The chance of TURP syndrome significantly increases when the prostate gland is larger than $45 \mathrm{~g}$, or the resection time is longer than $90 \mathrm{~min}$ (15). Most of all, one study showed that $14.7 \%$ of patients who underwent TURP required reoperation at the eighth year of follow-up (16). For these reasons, many alternative treatment options are been actively researched.

HoLEP is the most extensively studied laser therapy for BPH. Randomized control studies have shown that symptom improvement attained after HoLEP is comparable to that obtained following TURP, with favorable results including removed tissue weight, duration of catheterization, hospital stay, need for blood transfusions, and the absence of TURP syndrome (4,5,17-19). Similar treatment outcomes have been demonstrated when HoLEP was compared to open prostatectomy for the treatment of large prostates. Surgical time and removed tissue weight were better in open prostatectomy, but duration of catheterization, hospital stay and bleeding were better in HoLEP $(9,11,20,21)$. The rationale behind lower amount of removed tissue weight during HoLEP comes from vaporization effect during enucleation (5). These merits, proven in long-term follow-up studies, suggest that HoLEP is a viable alternative to TURP and open prostatectomy.

However, the major disadvantage of HoLEP is a steep learning curve to attain competency. The procedure requires specialized training and equipment. Based on their own experiences, Moody et al. and Kuntz et al. argued that a minimum of 30 procedures on smaller glands $(<50 \mathrm{gm})$ should be performed before attempting enucleation of larger adenomas using HoLEP. In their retrospective study, $\mathrm{Du}$ et al. reported that the surgeon became more confident with the HoLEP technique after about 15 cases which involved moderate size prostates (22). Shah et al. reported in their prospective study that 


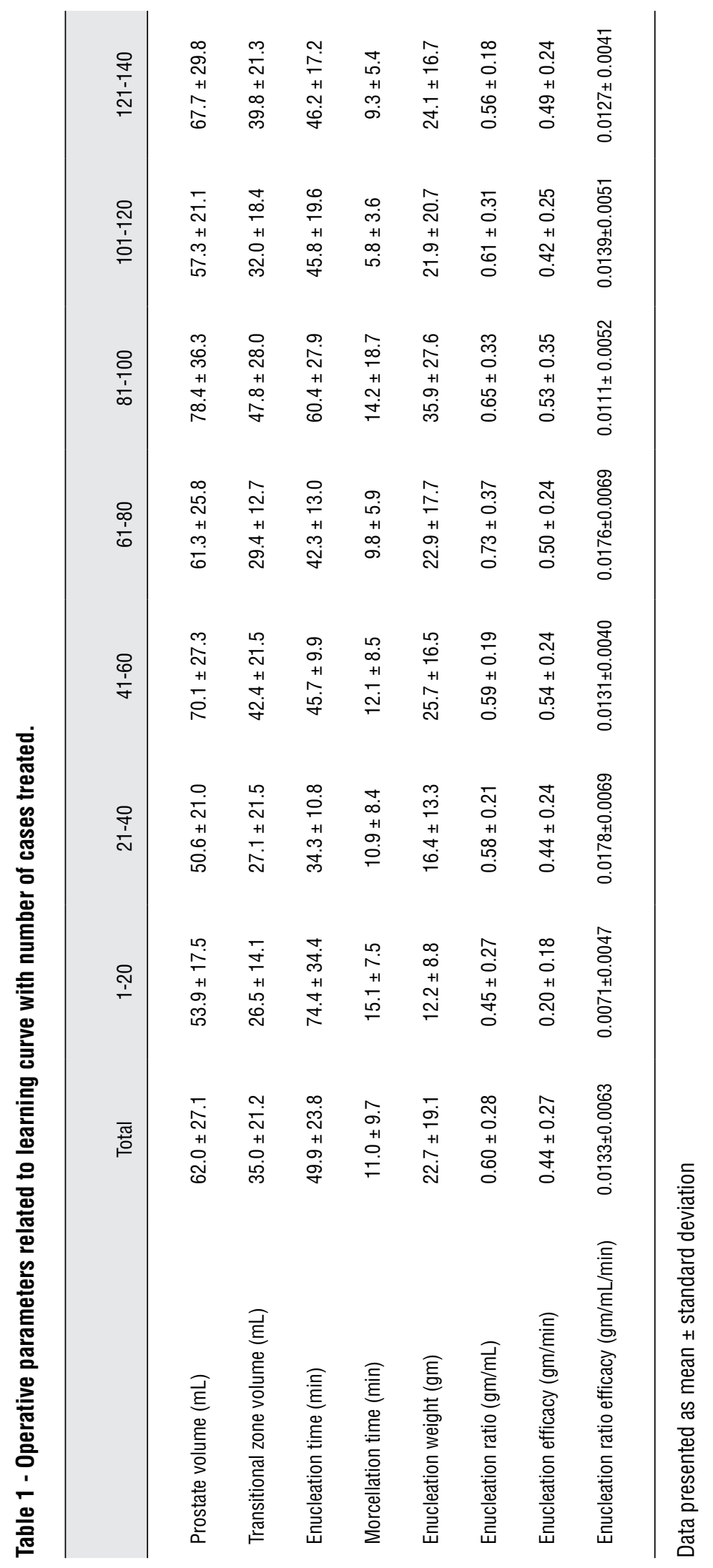


Table 2 - Preoperative and follow-up functional outcomes.

\begin{tabular}{lcccc}
\hline & Preoperative $(\mathrm{n}=140)$ & $\begin{array}{c}2 \text { wks }-1 \mathrm{mo} \\
(\mathrm{n}=129)\end{array}$ & $3 \mathrm{mo}(\mathrm{n}=91)$ & $\begin{array}{c}6 \mathrm{mo} \\
(\mathrm{n}=63)\end{array}$ \\
\hline Maximum flow rate $(\mathrm{mL} / \mathrm{sec})$ & $9.6 \pm 4.7$ & $19.3 \pm 9.2$ & $20.9 \pm 10.5$ & $21.2 \pm 8.2$ \\
Postvoid residual $(\mathrm{mL})$ & $86.5 \pm 124.6$ & $23.4 \pm 29.9$ & $27.4 \pm 42.3$ & $23.4 \pm 34.1$ \\
IPSS (total) & $18.8 \pm 7.7$ & $12.0 \pm 7.7$ & $6.8 \pm 5.5$ & $7.3 \pm 6.5$ \\
QoL & $4.2 \pm 1.2$ & $2.7 \pm 1.7$ & $2.0 \pm 1.4$ & $1.8 \pm 1.5$ \\
\hline
\end{tabular}

Data presented as mean \pm standard deviation. IPSS= international prostate symptom score; QoL=quality of life

Table 3 - Intra- and postoperative complications according to the number of cases treated.

\begin{tabular}{|c|c|c|c|c|c|c|c|c|c|}
\hline & $\begin{array}{l}\text { Clavien-Dindo } \\
\text { grade }\end{array}$ & Total & $1-20$ & $21-40$ & $41-60$ & $61-80$ & $81-100$ & $101-120$ & $121-140$ \\
\hline \multicolumn{10}{|l|}{ Intraoperative } \\
\hline Minor capsular perforation & I & 5 & 0 & 1 & 1 & 3 & 0 & 0 & 0 \\
\hline Bladder mucosal injury & 1 & 4 & 0 & 0 & 1 & 2 & 0 & 0 & 1 \\
\hline \multicolumn{10}{|l|}{ Immediate postoperative } \\
\hline Re-catheterization & ॥ & 9 & 2 & 2 & 2 & 3 & 0 & 0 & 0 \\
\hline Blood transfusion & II & 2 & 0 & 1 & 0 & 1 & 0 & 0 & 0 \\
\hline Transurethral coagulation & IIla & 2 & 0 & 1 & 1 & 0 & 0 & 0 & 0 \\
\hline Transient SUI & I & 6 & 2 & 1 & 1 & 1 & 1 & 0 & 0 \\
\hline Urinary tract infection & II & 1 & 0 & 0 & 0 & 0 & 0 & 1 & 0 \\
\hline \multicolumn{10}{|l|}{ Late postoperative } \\
\hline Urethral stricture & IIla & 1 & 1 & 0 & 0 & 0 & 0 & 0 & 0 \\
\hline Bladder neck contracture & IIIb & 1 & 1 & 0 & 0 & 0 & 0 & 0 & 0 \\
\hline Total sum/Total patients & & $31 / 27$ & $6 / 6$ & $6 / 4$ & $6 / 6$ & $10 / 8$ & $1 / 1$ & $1 / 1$ & $1 / 1$ \\
\hline
\end{tabular}

SUI = stress urinary incontinence

HoLEP can be performed effectively after about 50 cases, with an outcome comparable to that of experts (12). Their conclusion was based on enucleation efficacy analysis and complication rate. Seki et al. argued that HoLEP can be taught even without a proper instructor, and in that report at least 50 cases of operative experience was needed to at- tain competency (13). These results were derived from a plateau curve of tissue enucleation efficacy. We found that reports based on subjective experience or confidence concluded that HoLEP competency required 20-30 cases of experience $(6,11)$. On the other hand, reports based on enucleation efficacy concluded that at least 50 cases were needed 
Figure 1. Correlation between prostate size and enucleation efficacy. (A) Total prostate volume. (B) Transitional zone volume. (Linear regression with $95 \%$ mean prediction interval).


Figure 2. Changes in operative parameters related to learning curve in order of sequences. (A) Enucleation efficacy. (B) Enucleation ratio. (C) Prostate volume. (D) Enucleation time. (E) Enucleation ratio efficacy.
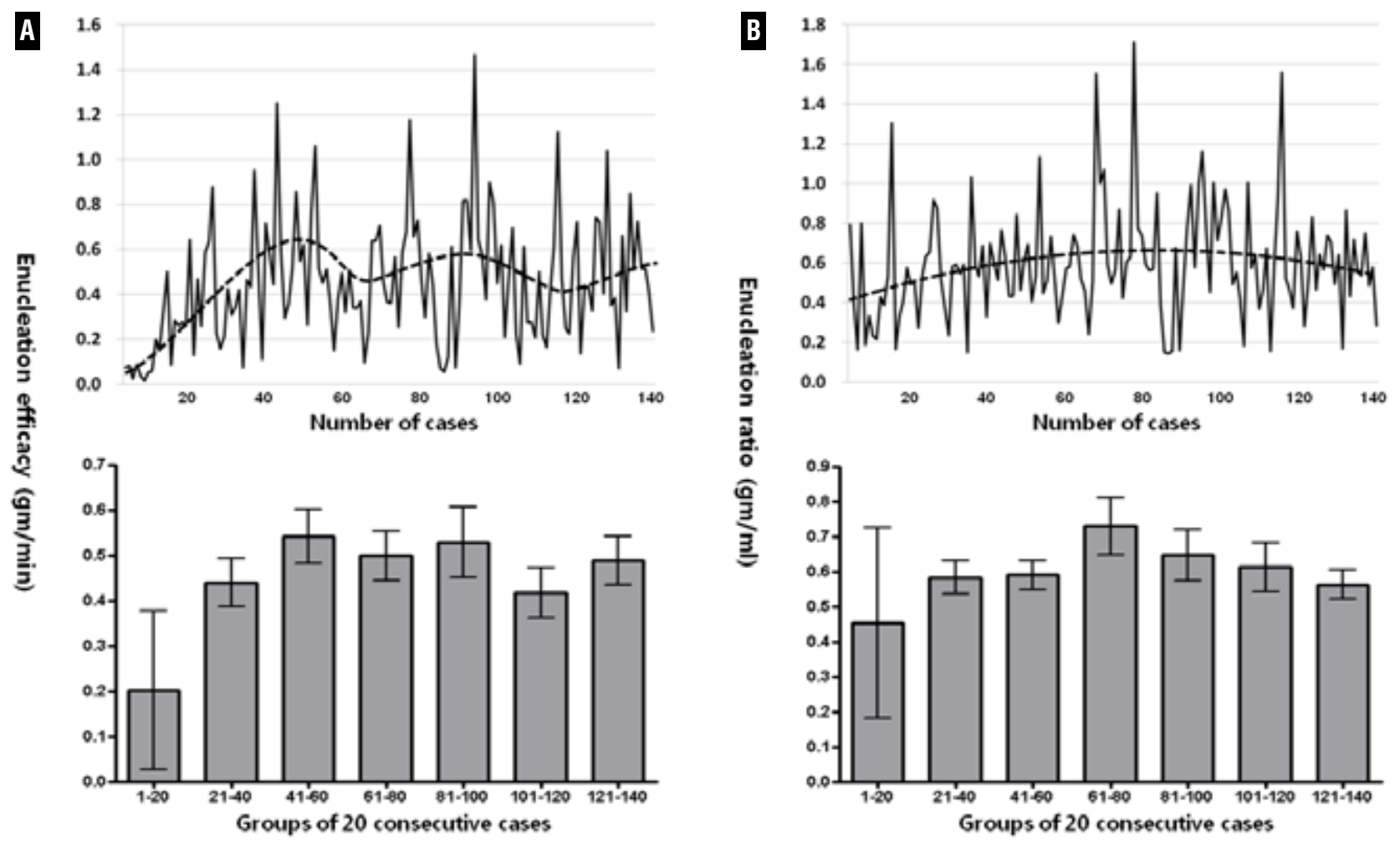

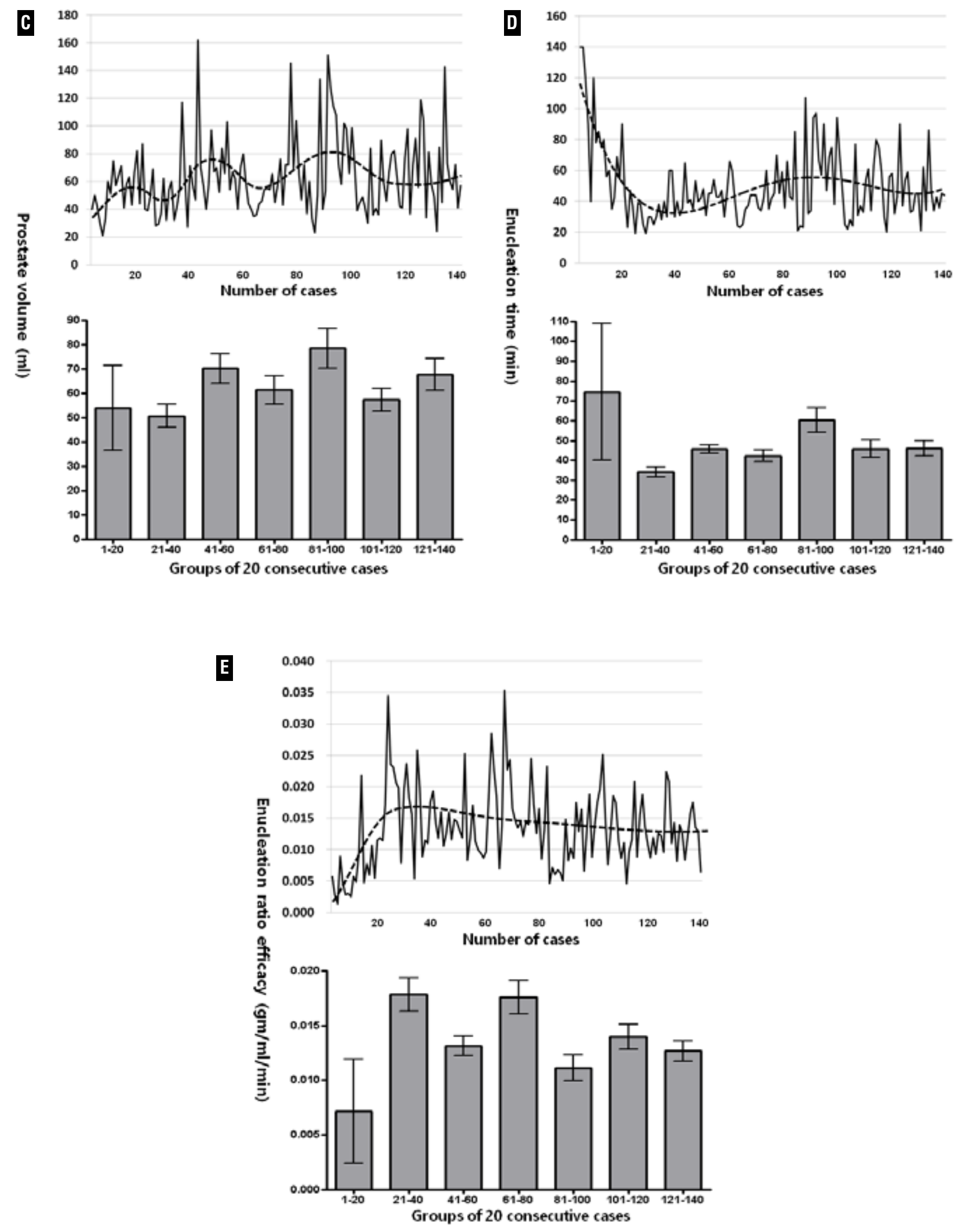
to attain competency $(12,13)$. Enucleation efficacy is considered to be a more objective parameter to estimate operative learning curve. However, there is a discrepancy between enucleation efficacy and self confidence regarding the HoLEP procedure.

In July 2008, our institution began offering HoLEP. There was no experienced urologist in the Republic of Korea at the time, and HoLEP was self-taught by reviewing expert videos. Our results, demonstrating quick symptomatic improvement and a reasonable complication rate, are consistent with that previously published (23). Moreover, while Placer et al. reported that persistent stress urinary incontinence $(4.8 \%)$ occurred during initial enucleation of large-sized prostates in the selftaught situation, there was no persistent stress urinary incontinence in our series (24).

In this study, enucleation efficacy increased in the initial cases, and the plateau was reached around the fiftieth case. In contrast, the enucleation ratio did not show significant difference. However, enucleation efficacy had a strong linear correlation with prostate size. This implies that HoLEP is more effective for larger prostates, and enucleation efficacy is also confounded by prostate size. There was no difference between the first 20 cases and the next 20 cases in terms of prostate volume, but the subsequent 20 cases were of significantly larger prostates than the prior 20 cases. Thus, during the first 40 cases the enucleation efficacy has increased mainly by technical improvement, and during the later period increased efficacy was obtained due to case selection of larger prostates after the surgeon had gained confidence. This can also be observed in the enucleation time curve. This phenomenon is consistent with a previous report (24).

As a result, we propose a new parameter, 'enucleation ratio efficacy', to estimate the operative learning curve for HoLEP. It is defined as enucleation ratio divided by enucleation time and this is identical to enucleation efficacy divided by transitional zone volume. This new parameter can eliminate the confounding effect of prostate size from enucleation efficacy. In this series, the correlation coefficient between enucleation ratio efficacy and prostate size was only -0.101 $(p=0.233)$. Furthermore, the enucleation ratio efficacy stabilized after 25 cases, and this observa- tion was consistent with the surgeon's confidence in his operative skills. We believe this parameter reflects the surgeon's skills more accurately than enucleation efficacy by eliminating size as a confounding effect. Both enucleation efficacy and enucleation ratio efficacy reduced after reaching the plateau. We think that it occurred because the surgeon, once having gained confidence, had more time for meticulous bleeding control and completing the procedure.

The clinical outcomes were not different between the groups along cases. In all patients, objective outcomes (maximum flow rate and post void residual volume) significantly improved immediately from the first visit. In contrast, subjective outcomes, especially IPSS total score, stabilized 3 months after surgery.

While the surgeon's competency to perform HoLEP could be attained after 25 cases, complications were significantly reduced after 80 cases, although they were mild. Overall, 19.3\% of patients experienced complications related to surgery. However, most of these complications were mild and transient. Clavien classification (25) III complications developed in 4 patients (2.9\%), and highergrade adverse events did not occur. Surgeons should be careful in minimizing complications after gaining confidence with their surgical skills by the lesson from this series. Seki et al. reported high incidence of urethral stricture (7\%) and they laid the responsibility to the larger nephroscopes (26Fr). However, only one patient (0.7\%) experienced urethral stricture in our series. We do not believe that a systematic use of a $26 \mathrm{Fr}$ working sheath could increase the incidence of urethral complications, if surgeon carefully performs HoLEP.

We believe that performing an extensive literature review on surgical technique and watching and analyzing videos of procedures recorded by an expert are very important. Moreover, we advocate repeated self-training with records and videos of their own cases. In doing so, the learning curve which is thought to be steep could be overcomed in a shorter period of time. This could be even more apparent if a surgeon already has considerable experience in endourological procedures. Despite the "self-taught" situation in our series, there was an overall low incidence of complications. 
In the analysis, there were three patients whose prostate volumes were less than $25 \mathrm{~mL}$. Their transitional zone volumes were between 8 - $9 \mathrm{~mL}$ and anatomical obstructions secondary to median lobe enlargement were found on urethrocystoscopy. These cases could be ideal candidates for transurethral incision of the prostate. However, we chose HoLEP rather than transurethral incision in an attempt to remove the whole adenoma. We included these cases in the study cohort, because that faithfully reflects our real practice.

Our study has several limitations. The major pitfall is the retrospective nature of the study. Notwithstanding, all consecutive patients were enrolled to avoid potential selection bias. Furthermore, all data were collected prospectively using a planned data registry form. It would be more informative if long-term follow-up results could be presented. However, we believe that surgical competency could be reasonably assessed with shortterm outcomes of six months. The other limitation is that the study was conducted on patients operated by one surgeon. Our proposed parameter, enucleation ratio efficacy, should be evaluated with several surgeons in the future, to determine if it is generally acceptable.

\section{CONCLUSIONS}

Our results demonstrated that the learning curve can be overcome after about 25 cases, even in a non-mentor-aided situation. We believe that a more appropriate parameter for estimating the learning curve is enucleation ratio efficacy rather than enucleation efficacy.

\section{ABBREVIATIONS}

$\mathrm{BPH}=$ Benign prostatic hyperplasia;

TURP = transurethral resection of the prostate;

$\mathrm{PVP}=$ photoselective vaporization of the prostate;

HoLEP = holmium laser enucleation of the prostate;

ThuLEP $=$ thulium laser enucleation of the prostate;

IPSS = International Prostate Symptom Score;

QoL = quality of life;

IRB = institutional review board;

SUI $=$ stress urinary incontinence

\section{CONFLICT OF INTEREST}

\author{
None declared.
}

\section{REFERENCES}

1. Arrighi HM, Metter EJ, Guess HA, Fozzard JL: Natural history of benign prostatic hyperplasia and risk of prostatectomy. The Baltimore Longitudinal Study of Aging. Urology. 1991; 38(1 Suppl): 4-8.

2. AUA guideline on management of benign prostatic hyperplasia (2003). Chapter 1: Diagnosis and treatment recommendations. J Urol. 2003; 170: 530-47.

3. Gilling PJ, Cass CB, Cresswell MD, Fraundorfer MR: Holmium laser resection of the prostate: preliminary results of a new method for the treatment of benign prostatic hyperplasia. Urology. 1996; 47: 48-51.

4. Montorsi F, Naspro R, Salonia A, Suardi N, Briganti A, Zanoni $\mathrm{M}$, et al.: Holmium laser enucleation versus transurethral resection of the prostate: results from a 2-center, prospective, randomized trial in patients with obstructive benign prostatic hyperplasia. J Urol. 2004; 172: 1926-9.

5. Gupta N, Sivaramakrishna, Kumar R, Dogra PN, Seth A: Comparison of standard transurethral resection, transurethral vapour resection and holmium laser enucleation of the prostate for managing benign prostatic hyperplasia of $>40$ g. BJU Int. 2006; 97: 85-9.

6. Kuntz RM, Lehrich K: Transurethral holmium laser enucleation versus transvesical open enucleation for prostate adenoma greater than $100 \mathrm{gm}$.: a randomized prospective trial of 120 patients. J Urol. 2002; 168: 1465-9.

7. Elzayat EA, Elhilali MM: Holmium laser enucleation of the prostate (HoLEP): long-term results, reoperation rate, and possible impact of the learning curve. Eur Urol. 2007; 52: 1465-71.

8. Gilling PJ, Mackey M, Cresswell M, Kennett K, Kabalin JN, Fraundorfer MR: Holmium laser versus transurethral resection of the prostate: a randomized prospective trial with 1-year follow up. J Urol. 1999; 162: 1640-4.

9. Kuntz RM, Lehrich K, Ahyai SA: Holmium laser enucleation of the prostate versus open prostatectomy for prostates greater than 100 grams: 5-year follow-up results of a randomised clinical trial. Eur Urol. 2008; 53: 160-6.

10. Humphreys MR, Miller NL, Handa SE, Terry C, Munch LC, Lingeman JE: Holmium laser enucleation of the prostate-outcomes independent of prostate size? J Urol. 2008; 180: 2431-5.

11. Moody JA, Lingeman JE: Holmium laser enucleation for prostate adenoma greater than $100 \mathrm{gm}$ : comparison to open prostatectomy. J Urol. 2001; 165: 459-62. 
12. Shah HN, Mahajan AP, Sodha HS, Hegde S, Mohile PD, Bansal MB: Prospective evaluation of the learning curve for holmium laser enucleation of the prostate. J Urol. 2007; 177: 1468-74.

13. Seki N, Mochida O, Kinukawa N, Sagiyama K, Naito S: Holmium laser enucleation for prostatic adenoma: analysis of learning curve over the course of 70 consecutive cases. J Urol. 2003; 170: 1847-50.

14. Madersbacher S, Alivizatos G, Nordling J, Sanz CR, Emberton M, de la Rosette JJ: EAU 2004 guidelines on assessment, therapy and follow-up of men with lower urinary tract symptoms suggestive of benign prostatic obstruction (BPH guidelines). Eur Urol. 2004; 46: 547-54.

15. Mebust WK, Holtgrewe HL, Cockett AT, Peters PC: Transurethral prostatectomy: immediate and postoperative complications. A cooperative study of 13 participating institutions evaluating 3,885 patients. J Urol. 1989; 141: 243-7.

16. Madersbacher S, Lackner J, Brössner C, Röhlich M, Stancik I, Willinger M, et al.: Reoperation, myocardial infarction and mortality after transurethral and open prostatectomy: a nationwide, long-term analysis of 23,123 cases. Eur Urol. 2005; 47: 499-504.

17. Kuntz RM, Ahyai S, Lehrich K, Fayad A: Transurethral holmium laser enucleation of the prostate versus transurethral electrocautery resection of the prostate: a randomized prospective trial in 200 patients. J Urol. 2004; 172: 1012-6.

18. Tan $\mathrm{AH}$, Gilling PJ, Kennett KM, Frampton C, Westenberg AM, Fraundorfer MR: A randomized trial comparing holmium laser enucleation of the prostate with transurethral resection of the prostate for the treatment of bladder outlet obstruction secondary to benign prostatic hyperplasia in large glands (40 to 200 grams). J Urol. 2003; 170: 1270-4.
19. Ahyai SA, Lehrich K, Kuntz RM: Holmium laser enucleation versus transurethral resection of the prostate: 3-year follow-up results of a randomized clinical trial. Eur Urol. 2007; 52: 1456-63.

20. Elzayat EA, Elhilali MM: Holmium laser enucleation of the prostate (HoLEP): the endourologic alternative to open prostatectomy. Eur Urol. 2006; 49: 87-91.

21. Naspro R, Suardi N, Salonia A, Scattoni V, Guazzoni G, Colombo $\mathrm{R}$, et al.: Holmium laser enucleation of the prostate versus open prostatectomy for prostates $>70 \mathrm{~g}$ : 24-month follow-up. Eur Urol. 2006; 50: 563-8.

22. Du C, Jin X, Bai F, Qiu Y: Holmium laser enucleation of the prostate: the safety, efficacy, and learning experience in China. J Endourol. 2008; 22: 1031-6.

23. Naspro R, Bachmann A, Gilling P, Kuntz R, Madersbacher $S$, Montorsi F, et al.: A review of the recent evidence (20062008) for 532-nm photoselective laser vaporisation and holmium laser enucleation of the prostate. Eur Urol. 2009; 55: $1345-57$.

24. Placer J, Gelabert-Mas A, Vallmanya F, Manresa JM, Menéndez $\mathrm{V}$, Cortadellas $\mathrm{R}$, et al.: Holmium laser enucleation of prostate: outcome and complications of self-taught learning curve. Urology. 2009; 73: 1042-8.

25. Dindo D, Demartines N, Clavien PA: Classification of surgical complications: A new proposal with evaluation in a cohort of 6336 patients and results of a survey. Ann Surg. 2004; 240: 205-13.

Correspondence address:

Dr. Seung-June Oh Department of Urology,

Seoul National University Hospital 101 Daehangno, Jongno-gu, Seoul, Korea

FAX: + $822742-4665$

E-mail: sjo@snu.ac.kr 


\section{EDITORIAL COMMENT}

There are very consistent publication in the literature demonstrating even the superiority of HoLep compared to TURP and open prostatectomy. However, the method continues to spread with difficulty, probably due to five factors. The difficulty of learning the technique, the need for morcelation, the need for investment, the existence of several other laser equipment for prostate surgery and the fact that TURP still solve the most of cases. The work has a very interesting approach, subtracting the effect on surgical time produced by large adenomas, demonstrating that the learning curve may be lower than expected and would not need a mentor. His weak point is the parameter with only one surgeon.

Dr. Sandro Faria Hospital Vera Cruz, Campinas Avenida Andrade Neves, 402 - Centro, Campinas

SP, 13013-908, Brazil

E-mail:sandro.farias@gmail.com

\section{EDITORIAL COMMENT}

HoLEP is, so far, the most extensively studied laser technique for treatment of BPH and a "steep learning curve" is the described major drawback of this method. In the present article, the authors evaluated, in a non-mentor-aided fashion, the ideal method to assess the learning curve of HoLEP. They concluded that the best method to estimate the operative learning curve is the enu- cleation ratio efficacy (enucleation ratio/enucleation time), rather than enucleation efficacy. What is remarkable in their study is the low overall complication rate considering their lack of experience. This means that urologists should be encouraged to start performing HoLEP as an option for larger prostates that are not suitable for TURP, since its complications seems to be mild and not frequent.

\footnotetext{
Dr. Alberto Azoubel Antunes Division of Urology University of Sao Paulo Medical School Rua Barata Ribeiro, 490 / cj 76 Sao Paulo, SP, 01308-000, Brazil E-mail: antunesuro@uol.com.br
} 